$7 \%, \mathrm{p}<0.05)$ then RA pts without HF. DAS28, CRP and ESR did not differ in two groups.

In order to identify factors associated with the risk of development of $\mathrm{HF}$, a step-by-step linear regression analysis was performed. The multiple coefficient of determination is $R^{2}=57.1(R-0.76, p<0.001)$ (Tabl.1).

Table 1. Risk factors of HF in patients with early rheumatoid arthritis

\begin{tabular}{lcccc}
\hline Model & $\begin{array}{c}\text { Non-standard coefficient } \\
\beta\end{array}$ & $p$ & \multicolumn{2}{c}{$95 \% \mathrm{Cl}$} \\
\hline Abdominal obesity, yes/ & 0,249 & 0,025 & 0,032 & 0,466 \\
no & & & & \\
\hline CRP, mg/l & 0,004 & 0,003 & 0,001 & 0,006 \\
Dyslipidemia, yes/no & 0,255 & 0,024 & 0,034 & 0,476 \\
AH, yes/no & 0,004 & 0,144 & 0,001 & 0,010 \\
TIM carotid arteries, mm & 0,758 & 0,026 & 0,091 & 1,423 \\
CAD, yes/no & 0,226 & 0,073 & 0,021 & 0,474 \\
\hline
\end{tabular}

According to ROC analysis, the diagnostic significance of studied factors was high with $88 \%$ sensitivity and $88 \%$ specificity.

Conclusion: HF mainly with preserved EF was found in $1 / 3$ of pts with early RA with high and moderate activity. Clinical manifestations of $\mathrm{HF}$ had low diagnostic value. The risk factors of HF in pts with RA were the level of CRP and traditional risk factors (abdominal obesity, AH, dyslipidemia), the value of TIM of carotid arteries and the presence of CAD. Disclosure of Interests: None declared

DOI: 10.1136/annrheumdis-2019-eular.5934

\section{AB0333 EFFECT OF OBESITY ON THE COURSE OF RHEUMATOID ARTHRITIS AND CARDIOVASCULAR RISK}

Svetlana Lapshina ${ }^{1}{ }^{2}$, Liutsiia Feiskhanova ${ }^{1}$ Luciya Kupkenova $^{1}$, Ridiya Sharafutdinova', Albina Yusupova' ${ }^{1}{ }^{1}$ Kazan State Medical University, KAZAN, Russian Federation; ${ }^{2}$ Republic Clinical Hospital, Kazan, Russian Federation

Background: The literature shows that the level of pro-inflammatory cytokines increases in obesity. High body mass index (BMI) is increasingly common in rheumatoid arthritis (RA), which can aggravate cardiovascular risks.

Objectives: The aim is to study the effect of obesity on the course of RA and cardiovascular risk.

Methods: 100 patients (male-7\%, female-93\%) aged from 21 to 81 years (average age $55 \pm 12.4$ ) with reliable RA were examined. High activity in DAS28 scale was observed in $68 \%$, moderate - in $30 \%$, low - in $2 \%$, rheumatoid factor (RF) positivity - in $88 \%$, ACCP - $81 \%$. DMARDs received $78 \%$, glucocorticosteroids $60 \%$ of patients. Arterial hypertension (AH) was present in $45 \%$ of patients. BMl ranged from 15 to $46.5 \mathrm{~kg} / \mathrm{m}^{2}$ (average 26.8 \pm 5.7 ). The patients were divided into three groups: the 1st $(n=38)$ with a normal BMI up to $25 \mathrm{~kg} / \mathrm{m}^{2}$, the $2 n d(n=24)$ - with heightened BMI 25-29.9 kg/m ${ }^{2}$, the 3rd group $(n=28)$ - more than $30 \mathrm{~kg} / \mathrm{m}^{2}$. Patients were examined in standard laboratory tests, all of them had echocardiogram.

Results: Patients in the groups with normal and heightened BMI had no statistical differences in manifestations of articular syndrome. In the 3rd group with obesity reliably higher (pThe level of systolic blood pressure (BP) correlated with BMI, although even in the group with obesity it was 136.4 \pm 21.9 (pThe increase in LVMl correlated (pConclusion: RA in patients with obesity is characterized by a higher activity first of all because of pain syndrome. Increased BMl leads to bad prognostic myocardial changes in patients with RA, while cholesterol and blood pressure may stay within the normal range. This causes the need of using the echocardiography for this group of patients.

\section{REFERENCES}

[1] rheumatoid arthritis, body mass index

Disclosure of Interests: None declared DOI: 10.1136/annrheumdis-2019-eular.6618

\section{$\mathrm{AB} 0334$ \\ THE OVARIAN RESERVE MEASURING THE ANTI- MÜLLERIAN HORMONE IS NOT DIMINISHED IN PATIENTS WITH RHEUMATOID ARTHRITISCOMPARED TO THE HEALTHY POPULATION}

Mireia Lopez Corbeto ${ }^{1}$, Andrea Pluma Sanjurjo ${ }^{1}$, Sergio Hilario Martinez ${ }^{2}$, Maria Lopez Lasanta ${ }^{1}$, Agusti Sellas-Fernández ${ }^{3}$, Sara Marsal ${ }^{3} .{ }^{1}$ Hospital Universitari Vall d'Hebron, Rheumatology, Barcelona, Spain; ${ }^{2}$ Parc Cientific de Barcelona, Barcelona, Spain; ${ }^{3}$ Hospital Vall D Hebron, Rheumatology, Barcelona, Spain

Background: Rheumatoid Arthritis (RA) is the most prevalent chronic inflammatory arthritis, affecting $0.5-1 \%$ worldwide population and predominates in females. Altered fertility has been reported due to a decrease in ovarian reserve secondary to sustained inflammation. The anti-Müllerian Hormone (AMH) is currently the most reliable biomarker of ovarian reserve. However, few and contradictory studies have been reported to analyze the relationship between fertility in RA women patients and $A M H$. Objectives: The aim of present study is to determine the AMH serum concentrations in a long-standing RA patients and control group. We also sought to determine the correlation between $\mathrm{AMH}$ serum levels and disease activity measured by different parameters and the effect of biological DMARDs.

Methods: Serum AMH levels were measured in 60 women with longstanding RA aged 20-50 y.o. and compared to 59 healthy women. AMH was assessed by ELISA (Gen II Beckman Coulter Inc.) and a large data set of clinical and molecular data was annotated. Demographic parameters, RA disease activity measured by DAS28 score and inflammatory biomarkers such as ESR, CRP, lymphocyte CD4+, CD8+, NK cells, IL-10 and IL-6 were determined. A comprehensive gynecological self-administered questionnaire was given. Serum AMH levels were age-correlated. Differences between groups were calculated using Student's t-test or Mann-Whitney $U$ test for continuous variables and Fisher's exact test for categorical variables. Multivariate analysis was conducted by the partial correlation coefficient. Linear regression analysis was performed to study the effect of different variables on proportional AMH change. $P$ value $<0.005$ were considered significant.

Results: The median age was similar in AR and control groups (37.4 \pm 6.23 vs $37.3 \pm 6.27 P=0.937$ ). Mean disease duration was $8.37 \pm 5.36$ years. The number of previous treatments was $<3$ in $71.7 \%$ of patients and $\geq 3$ in $28.3 \%$. Disease activity measured by DAS28 was $2.89 \pm 1.54$. The age-adjusted mean serum concentration of HAM was $1.27 \mathrm{ng} / \mathrm{ml}$ [IQR 0.42; 2.24] in RA patients and $1.31 \mathrm{ng} / \mathrm{ml}$ [IQR 0.46; 3.09] in controls $(P=0.608)$. Neither disease activity $(P=0.862)$, nor current or previous bDMARDs treatments $(P=0.871)$ were associated with HAM levels. However, a negative linear correlation was observed between HAM and IL-10 levels $(P=0.033)$.

Conclusion: Our study shows that ovarian reserve determined by HAM serum levels is not reduced in rheumatoid arthritis patients compared with healthy controls. In our series, HAM levels were not affected by disease activity however a significant correlation was observed between HAM and IL-10 levels. These results support the role of cytokines profile in the female reproductive system and will focus further investigations in this critical area, mainly once biological DMARDs have be recommended in RA pregnant patients.

\section{REFERENCES}

[1] Brouwer J, Fleurbaaij R, Hazes JM, Dolhain RJ, Laven JS. Subfertility in rheumatoid arthritis is often unexplained or caused by anovulation. Arthritis Care Res (Hoboken). 2016.

[2] Brouwer J, Hazes JM, Laven JS, Dolhain RJ. Fertility in women with rheumatoid arthritis: influence of disease activity and medication. Ann Rheum Dis. 2015;74(10):1836-1841.

[3] Brouwer J, Laven JS, Hazes JM, Schipper I, Dolhain RJ. Levels of serum anti-Mullerian hormone, a marker for ovarian reserve, in women with rheumatoid arthritis. Arthritis Care Res (Hoboken). 2013;65(9):1534-1538.

[4] Del Junco DJ, Annegers JF, Coulam CB, Luthra HS. The relationship between rheumatoid arthritis and reproductive function. $\mathrm{Br} J$ Rheumatol. 1989;28 Suppl 1:33; discussion 42-35.

[5] Dewailly D, Andersen CY, Balen A, et al. The physiology and clinical utility of anti-Mullerian hormone in women. Hum Reprod Update. 2014;20 (3):370-385.

Disclosure of Interests: None declared

DOI: 10.1136/annrheumdis-2019-eular.3950 